\title{
Some fundamentals of handheld snow surface thermography
}

\author{
C. Shea ${ }^{1}$ and B. Jamieson ${ }^{1,2}$ \\ ${ }^{1}$ Department of Geoscience, University of Calgary, 2500 University Drive NW Calgary, Alberta, T2N 1N4, Canada \\ ${ }^{2}$ Department of Civil Engineering, University of Calgary, 2500 University Drive NW Calgary, Alberta, T2N 1N4, Canada
}

Received: 2 July 2010 - Published in The Cryosphere Discuss.: 27 August 2010

Revised: 10 December 2010 - Accepted: 9 January 2011 - Published: 2 February 2011

\begin{abstract}
This paper presents the concepts needed to perform snow surface thermography with a modern thermal imager. Snow-specific issues in the 7.5 to $13 \mu \mathrm{m}$ spectrum such as ice emissivity, photographic angle, operator heating, and others receive detailed review and discussion. To illustrate the usefulness of this measurement technique, various applications are presented. These include detecting spatial temperature variation on snow pit walls and measuring the dependence of heat conduction on grain type.
\end{abstract}

\section{Introduction}

Many processes depend on thermal exchange at the surface of snow. For avalanche prediction, the persistent weak layers of surface hoar (Hachikubo and Akitaya, 1997) and nearsurface facets (Morstad et al., 2007) form due to sustained thermal gradient. For hydrology, shortwave albedo - and thus radiation balance - changes as a direct result of surface grain type (Armstrong and Brun, 2008, p. 55), which follows from snow surface metamorphism via grain temperature and temperature gradient (McClung and Schaerer, 2006, p. 66).

In contrast to traditional contact thermometers, such as thermistors, which obtain a temperature by becoming the same temperature as their measured subject, remote thermal sensing provides a way to measure the thermal infrared emissions of a material surface without contact. By using a radiation sensor in the longwave range, and correcting for interference and the longwave emissivity of a material, the temperature of the material may be obtained. This idea has existed for quite some time; the first patent for an infrared thermometer was granted in 1899, and the Landsat satellite launch in 1978 included a spatial sensor in the thermal range (Lillesand et al., 2008).

Correspondence to: C. Shea (cashea@ucalgary.ca)
Space-based thermal sensing can provide a spatial image, but it cannot provide a high spatial resolution measurement like a handheld infrared point thermometer can. Thermography, also known as infrared thermal photography, bridges this gap. This paper discusses sensing of snow via handheld thermography. Scales include distances from a few kilometers to less than one meter. The bandwidth varies by equipment; this paper discusses the thermal infrared spectrum of 7.5 to $13 \mu \mathrm{m}$, a common spectral span for handheld thermal imagers.

Hand-held thermography, in contrast to space-based sensing, brings a host of new concerns as well as new abilities. This paper demonstrates how this technique has been used already and how it may be used in the future. Space-based thermal sensing has received attention in the previous work discussed throughout this paper. To date, no other paper has provided a specific presentation and discussion of use of snow surface thermography with these spatial resolutions and distances, despite it offering a variety of research possibilities. Thus, this paper attempts to provide both a physical and practical basis for using handheld thermography for sensing snow.

\section{Motivation}

The surface of snow can heat and cool at an astonishingly fast rate. As shown in the Applications section below, snow may be heated by an external heat source to $14^{\circ} \mathrm{C}$ above the ambient temperature, and portions of the surface can then reequalize with the ambient air, decreasing by $14^{\circ} \mathrm{C}$, within minutes.

The speed with which thermographs may be taken can record and measure many snow processes. Real-time video can capture spatial changes continuously, and even single thermographs can capture data that otherwise would be impossible to obtain point-by-point. Figure 1 shows but one example: a still-cold avalanche bed surface and warm crown

Published by Copernicus Publications on behalf of the European Geosciences Union. 


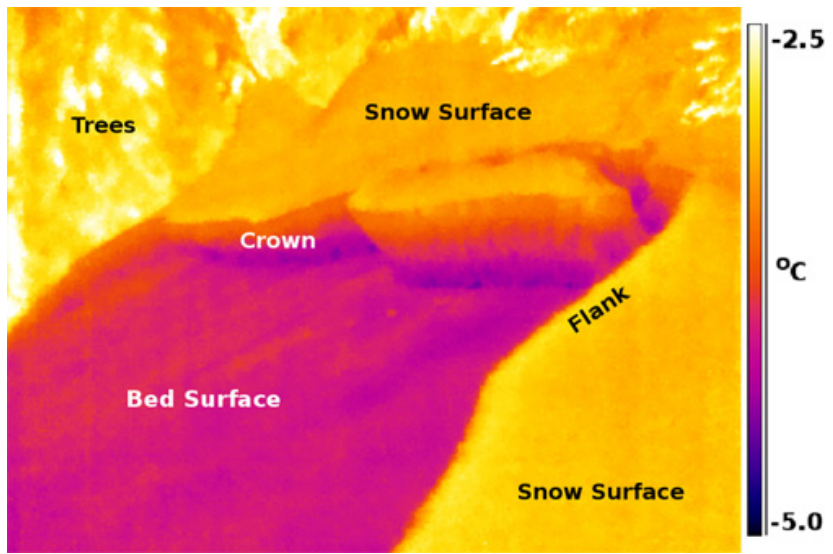

Fig. 1. Bed surface and crown of a slab avalanche, approximately $5 \mathrm{~min}$ after release. The thermograph was taken approximately $3 \mathrm{~m}$ from the labelled flank, and the crown depth is $\sim 40 \mathrm{~cm}$.

fracture, minutes after the slab avalanche occurred. The measurement of the temperature below the entire avalanche failure layer at once would be impossible without handheld thermography.

Thermography not only provides a different view of known effects, but some applications - such as an unexpected instance of an inverse relation between conduction speed and snow density described in Sect. 7.2 - reveal situations which are currently neither well understood nor well documented. Thermography provides new ways to measure these processes.

\section{Basic theory}

A thermal imager measures the amount of thermal-band radiation that reaches its sensor. All materials emit radiation in a way that can be predicted ideally by the Stefan-Boltzmann law. The Stefan-Boltzmann law states that emissivity $\epsilon$, temperature $T$ in $\mathrm{K}$, and watts output per square meter $P$ are related by:

$P=\epsilon \sigma T^{4}$

where $\sigma$ is the Stefan-Boltzmann constant $(5.67 \times$ $10^{-8} \mathrm{~J} \mathrm{~m}^{-2} \mathrm{~s}^{-1} \mathrm{~K}^{-4}$ ). The emissivity $\epsilon$ is material-specific and wavelength-specific, and it always lies between zero and one. An $\epsilon$ value of one indicates an ideal radiation emitter, also known as a blackbody.

The Stefan-Boltzmann law directly links emissions with temperature, and thus an observer may calculate the temperature of a material by measuring its radiation emission.

Another step in thermography is knowing how much emission is coming from one's subject of interest, and how much is coming from reflection and materials between the subject and the sensor. By Kirchoff's Law, the emissivity of a material in thermal equilibrium defines the fraction of energy of a given wavelength it emits $\epsilon$, the fraction it absorbs $A$, and the fraction it reflects $r$, where $\epsilon=A$ and:

$r=1-\epsilon$

Kirchoff's Law indicates that materials with high emissivity absorb almost all incident energy in the thermal spectrum and reflect very little. This makes them easy to image via thermography since most of the measured emissions at least at short ranges - are from the material of interest. Conversely, materials with low emissivity reflect more of the surrounding temperature - known as downwelling radiation - and larger corrections must be made.

Finally, these equations assume an ideal flat surface which is photographed directly along its surface normal line. Emittance is also a function of angle from surface normal. That is, even very diffuse emitters produce more radiation at an angle of 0 degrees from normal (directly facing the subject plane) than off to one side or another, falling off in theory via a cosine relationship with the angle from surface normal (Wolfe and Zissis, 1978, p. 1-6). When referring to this angle, which radiation exits along while leaving a surface, the term exitant angle is often used.

Unless pointed precisely along surface normal to a truly smooth surface, a thermal camera measures the radiation emitted along many different non-zero exitant angles throughout its frame. Thus, for thermography, the term photographic angle refers specifically to the exitant angle between the camera sensor and the center of the subject.

\section{Equipment}

Thermal imagers have significantly reduced in price over the last decade. Currently an imaging system that provides adequate resolution of at least $320 \times 240$ pixels, a betterthan $2{ }^{\circ} \mathrm{C}$ accuracy for absolute temperature, and a $0.5 \mathrm{mK}$ between-pixel sensitivity within a single image can be purchased from multiple companies for under US $\$ 15000$. The experiments described in this paper use a FLIR B300. Such equipment is often also portable in a backpack with room for other field materials, and is capable of operating below $-25^{\circ} \mathrm{C}$ for thirty minutes - at which point the limitation is the comfort of the field operator.

Modern thermal imagers require a factory calibration in a near-blackbody setting. Yet camera drift seems minimal: after taking over 700 field images, the imager used for experiments in this paper still measured $0.0^{\circ} \mathrm{C}$ for clean slush water through $1 \mathrm{~m}$ of inside air.

Many modern thermal imagers, including the one used for the applications in this paper, use a microbolometer containing many pixel-type sensors. Upon absorbing radiation particles, these pixels change some measurable property such as resistance. Material-level changes in measured pixel differences, then, are often called raw voltages. These voltages 
are then directly processed by the thermal camera into a measure of temperature, and a temperature value at this stage is known as a brightness temperature.

An uncorrected brightness temperature may be considerably different than the actual temperature of the subject. To estimate this actual temperature, thermographs need to be field calibrated - as is true for all materials - and additional corrections can be needed specifically for snow.

For most modern thermal imagers, basic corrective values such as emissivity and humidity may be entered directly into the thermal imager to use the correction specific to the camera. Some imagers also offers manipulation of integration times - a similar concept to exposure in visual photography - and further corrective factors. The individual algorithms for atmospheric and other corrections vary by equipment and are not discussed here.

The field calibration and snow-specific details, however, are addressed in-depth in the next sections. Each section presents its specific consideration, related previous work, and any new supplemental analysis together. Following that, the section entitled Applications contains a selection of possible uses for snow surface thermography, and a short summary concludes the paper.

\section{Field calibration of images}

The following subsections outline what information a user may need in order to properly calibrate a thermal image, including material emissivity, sources of external radiation and radiation interference, and distance to subject.

\subsection{Emissivity}

The high thermal emissivity $\epsilon$ of snow makes it easy to thermally image. Snow emissivity has been variably found to be 0.98 for frost (Wolfe and Zissis, 1978, p. 2-77), above 0.98 for small-grained snow under $1000 \mu \mathrm{m}$ (Dozier and Warren, 1982), 0.96 for flat solid ice and water (Wolfe and Zissis, 1978, p. 2-77), and as low as 0.8 for old snow (Wolfe and Zissis, 1978). Measurements at specific wavelengths (e.g. $10 \mu \mathrm{m}$ ) have seen emissivities as high as 0.995 (Dozier and Warren, 1982) and 0.997 (Hori et al., 2006).

Inversely, work on the thermal reflectance of snow (Salisbury et al., 1994a) shows $r$ to be less than $2.3 \%$ between the 4 to $14 \mu \mathrm{m}$ wavelengths. This holds for many snow types: granular, fine, wet, and dry; newly fallen snow reflected less than $1 \%$ between 4 to $14 \mu \mathrm{m}$.

For non-bandwidth specific measurements, 0.99 and 0.98 seem to be good general $\epsilon$ values for use in dry seasonal snow thermography.

For most of the 7.5 to $13 \mu \mathrm{m}$ spectrum, the emissivity is greater than this (Salisbury et al., 1994a; Dozier and Warren, 1982). However, the largest deviation that reaches 0.98 and below occurs at wavelengths near $11 \mu \mathrm{m}$ and longer. Wien's displacement law places the peak wavelength of snow emission at $10.6 \mu \mathrm{m}$ for snow at $-0^{\circ} \mathrm{C}$, and $11.0 \mu \mathrm{m}$ at $-10^{\circ} \mathrm{C}$. Bandwidth-specific distributions may be found in Dozier and Warren (1982) and Salisbury et al. (1994a).

\subsection{External natural influences}

Although the high emissivity of snow reduces the amount of correction needed, external energy sources still have impact.

Solar emission provides very little thermal infrared to be either absorbed or reflected. Most of the solar heating of snow is linked with daily maximum shortwave input (Armstrong and Brun, 2008). The radiation from the sun irradiates the top of the atmosphere with less than $1 \mathrm{~W} \mathrm{~m}^{-1} \mu \mathrm{m}^{-1}$ for the $7 \mu \mathrm{m}$ wavelength and longer (Wolfe and Zissis, 1978, p. 3-36), as compared with over $2000 \mathrm{~W} \mathrm{~m}^{-1} \mu \mathrm{m}^{-1}$ at a wavelength of $0.45 \mu \mathrm{m}$, or visible violet light.

Although the sun contributes very little electromagnetic radiation in the thermal wavelengths, water vapour in the atmosphere can affect the amount of thermal radiation reaching the ground. Other atmospheric constituents such as ozone $\left(\mathrm{O}_{3}\right)$, methane $\left(\mathrm{CH}_{4}\right)$, and carbon dioxide $\left(\mathrm{CO}_{2}\right)$ also have absorptive and emittive windows in the 7.5 to $13 \mu \mathrm{m}$ spectrum (Wolfe and Zissis, 1978), but these have little influence when the camera and subject are in the troposphere, and photos are taken in alpine areas with little air pollution. If such materials were to be present in the atmosphere in significant amounts, atmospheric interference could be minimized by using short distance photography.

The larger effect of water vapour can be predicted by its emissivity curve, which is similar to that of ice (Dozier and Warren, 1982). Typically, water vapour becomes heated by solar shortwave and emits diffusely, including in the downward direction toward the snow surface. A thick cloud can easily emit as much thermal radiation toward the snow as the snow emits out toward space, making clouds a much greater effect in the thermal spectrum than the sun.

Confirmation for this comes easily. A diffusing and highly reflective material such as crumpled aluminum foil - thermal $\epsilon=0.05$ (Wolfe and Zissis, 1978) - or gold plating - thermal $\epsilon=0.06$ (Salisbury et al., 1994b) - may be used to measure the downwelling atmospheric radiation. Care should be taken to make a truly diffuse reflector that reflects nearly equally in all directions, and, when used, the reflecting material should not be allowed to heat up via shortwave absorption (e.g. sun exposure) during measurement nor shaded from the emitting source of interest.

Such diffuse reflectors were placed on the ground in thick cloud conditions with the emissivity set for ice (0.98). Five temperatures - four from different sides of the reflector at $45^{\circ}$ photographic angles (see Sect. 6.3 below for a full description of photographic angle) and one facing straight down at the reflector were taken and averaged to obtain one reflected temperature measurement. Four such experiments were carried out for air temperatures in clouds between $+1^{\circ} \mathrm{C}$ and 
$-7^{\circ} \mathrm{C}$, with clouds up to $500 \mathrm{~m}$ above the surface. The reflected temperatures were always within $3{ }^{\circ} \mathrm{C}$ of the air temperature within the clouds, which were obtained from a remote weather station. This is in sharp contrast to five additional experiments under a clear sky, where the reflected temperature equaled the minimum equipment temperature, or $-40{ }^{\circ} \mathrm{C}$.

These experiments do not attempt to generalize the complex mechanism of downwelling atmospheric longwave radiation; extensive and more specific work such as that from Sugita and Brursaert (1993) exists on the topic. Rather, as thermography temperature is directly calculated from detected emissions, these experiments simply imply that (a) thermal emissions from a thick cloud with the above temperatures are on the order of emissions from snow at the above temperatures, and (b) simple diffuse reflectors can give the operator an idea as to whether the atmosphere is contributing significant longwave radiation.

External natural influences can be corrected for in various ways. Thermal imagers allow the user to input a value for humidity for corrections. Some imagers allow the user to input reflected apparent temperature, which allows the imager to account for downwelling radiation.

However, imagers often only allow one value for humidity or reflected temperature per image. With a complex scene including ice lenses, dense snow, and other conditions packed into one area, it can be useful to the user to know whether external influences will appear as higher or lower brightness temperatures. For example, if an ice lens of interest consistently appears warmer than the surrounding snow in cloudy conditions, it may be of interest to photograph the ice lens in similar but clear conditions as well.

\subsection{Distance to subject}

For close subjects within a few meters, proper calibration is easier than at longer distances. For typical snow and air temperatures and all other things being equal, the difference in measured temperature between 0.99 and 0.98 emissivity is less than $0.1{ }^{\circ} \mathrm{C}$ error while operating at one meter distance or less because the effect of intervening water vapour in the air is small.

At a kilometer of distance, poorly calibrated values within a range of usual winter atmospheric temperatures $(+10$ to $-10^{\circ} \mathrm{C}$ ) can cause around $4{ }^{\circ} \mathrm{C}$ of error between the thermal brightness seen at-camera and actual surface temperature. This is partly due to the falloff of radiation power density reaching the sensor - approximated by the inverse square law for large distances (Wolfe and Zissis, 1978, p. 1-32) and partly due to an inability to capture the variance in water vapour temperature and density over large distances with single values for air temperature and humidity.

As is discussed in depth below, at shorter distances the primary source of error is the angle of photography creating a different brightness temperature than the one desired, as discussed in Sect. 6.3, and operator heating, as discussed in Sect. 6.4.

At longer photographic distances, variability in air humidity and temperature have the potential to generate the largest amount of error due to there simply being more between the subject and the sensor. Also, at longer photographic distances fine spatial features will blur more than in visual photography. This is due to the power density - and thus irradiance - falloff being dependent on the power of the emission itself, where longwave radiation has less power than visual light.

\section{Snow-specific considerations}

In addition to properly calibrating each thermograph with the information above, the user should be further aware of some snow-specific nuances. These include times when the snow is heated below its surface by shortwave radiation, the effect of different ice morphology on reflection properties, the different uses for different photographic angles, and heating of the snow by the camera operator.

\subsection{Solid state greenhouse effect}

Snow as a material is subject to a phenomenon known as the solid state greenhouse effect (Brandt and Warren, 1993), where shortwave radiation may heat the snow below the surface but not necessarily at the surface. Depending on the porosity of the uppermost snow layer, this may provide variable thermal imaging of the snow surface.

Maximum daytime temperatures in a snowpack being found below the surface during clear, sunny conditions is a subject of some debate, as it sometimes occurs and sometimes does not (Fierz, 2010; Morstad et al., 2007; Brandt and Warren, 1993) for not-yet-fully understood reasons. The general theory states that, for a greenhouse effect to occur, the conduction of the snow above the point of solar heating must be poorer than the surface as an emitter. Since snow is more transparent to shortwave radiation than it is to thermal radiation, one can see that snow may heat below its surface where it absorbs incoming shortwave radiation, and emit efficiently at its surface to release longwave radiation.

If the shortwave radiation-generated heat at depth cannot conduct through the ice lattice back to the surface efficiently, this would trap heat below the surface. In turn, due to continued longwave radiation emission, this allows a skin at the surface to get cooler than the underlying warmed snow layer, which then remains warmer than the snow underlying it in turn. Without the greenhouse effect, the expected state of seasonal snow is for the surface to be the warmest portion of the snow during the day and the coolest portion at night (McClung and Schaerer, 2006, p. 52). 


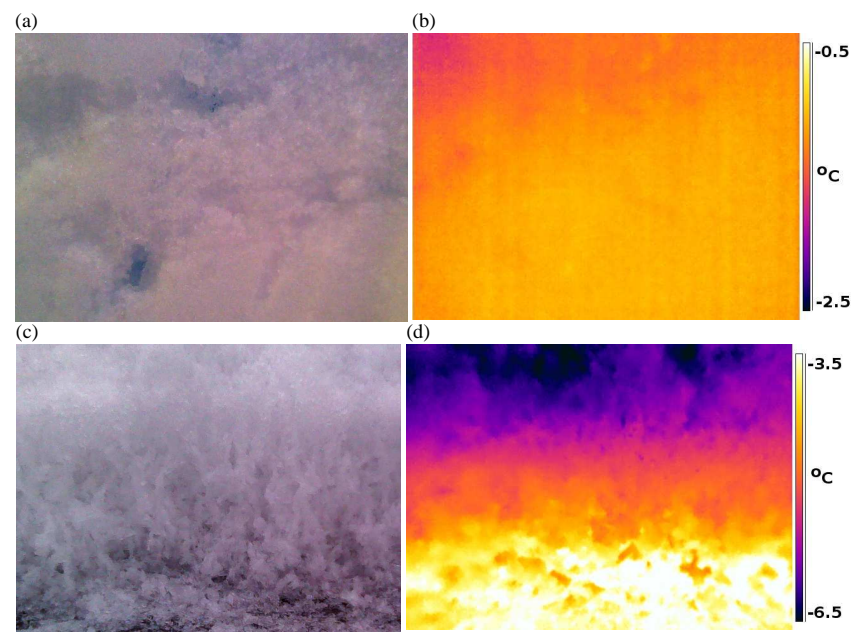

Fig. 2. Left: visual spectrum photographs of two areas with complex surface and grain qualities. Right: thermographs depicting the same areas. Images (a) and (b) are of a visually complex crust with relatively uniform temperatures. The images capture an area $\sim 30 \mathrm{~cm}$ in width. Images (c) and (d) are of a visually complex layer of depth hoar with complex temperatures. The images capture an area $\sim 10 \mathrm{~cm}$ in width.

\subsection{Snow morphology}

\section{Grain size and type}

The effect of grain size on emissivity has been studied for grains with radii 50 to $1000 \mu \mathrm{m}$ (Dozier and Warren, 1982), and thermal emissivity differences are less than 0.005 for wavelengths of 7 to $15 \mu \mathrm{m}$. This is in sharp contrast to, say, $1.3 \mu \mathrm{m}$ in the near infrared spectrum where albedo - i.e. total diffuse reflectivity - ranges from 0.2 to 0.6 depending on grain radius (Armstrong and Brun, 2008, p. 56).

Although this angle dependency is covered in more detail in Sect. 6.3, flat oriented and non-diffusely reflecting ice forms such as ice lenses need be photographed with some care. In such cases, one can imagine that unwanted reflected radiation may be much more intense at certain angles.

As snow becomes more morphologically similar to flat water, its emissivity decreases. Coarse refrozen granular crusts have been found to have emissivities close to that of water $(\epsilon=0.96)$ although finer grained crusts still mimic granular snow $(\epsilon=0.98)$, as found by Salisbury et al. (1994a). In the same work, the moisture content of granular snow (wet versus dry) appears to have little overall effect on emissivity, although wet snow displays lower reflectance by 0.005 in the 10 to $14 \mu \mathrm{m}$ range.

Hori et al. (2006) found that emissivity decreases slightly with increasing snow grain coarseness. Fine grained snow showed an emissivity range of 0.984 to 0.997 . Bare ice, on the lower extreme, ranged from 0.949 to 0.993 .

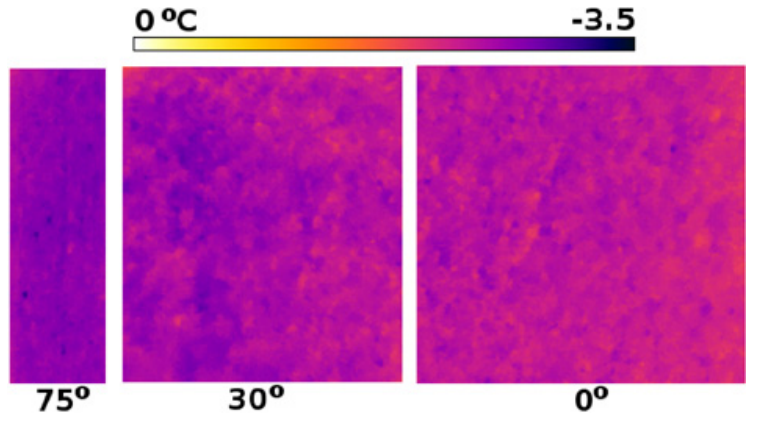

Fig. 3. Thermographs of the same $20 \times 20 \mathrm{~cm}$ area at a 75,30 , and 0 degree photographic angle.

Figure 2 photographically demonstrates the relative independence of thermal emission and grain size and type. Large variation in grain size and type can exist both with (Fig. 2c and d) and without (Fig. 2a and b) corresponding large thermal variation.

\section{Grain interactions}

In laboratory experiments to measure infrared material interactions, Salisbury et al. (1994b) found that some fine powders naturally exhibited clumping, e.g. "bridging and void formation". This tendency created both an uneven surface and conditions for poor thermal conductivity. The combination of these two factors, they proposed, would create not only a steep temperature gradient between material surface and air due to the poor material conductivity, but also between different parts of the surface; specifically, the peaks of clumps and the valleys between them.

Though their experiments used quartz powder, this clumping phenomenon is a familiar one in some undisturbed new snow dendritic crystal surfaces. Experiments with similar types of powders with uneven surfaces of rapidly lessening density toward the surface (such as fresh snow) can deviate from Kirchoff's Law by as much as 6 percent (Salisbury et al., 1994b), perhaps affecting how the reflectance of clumped snow should be treated.

When combined with the solid state greenhouse effect detailed above, the surface of snow can be quite complex in its thermal layering. This subject and its pertinence to snow warrants further study. Figure 3 shows an instance of clumped new snow creating this type of layered thermal effect. Choosing the correct photographic angle, as discussed further below along with Fig. 3, may help the user measure the desired thermal layer.

\subsection{Photographic angle}

Different photographic angles measure different attributes of the snow surface. Dozier and Warren (1982), for space-based sensing purposes, found that apparent snow emissivity can vary by as much as 0.02 over the hemispheric angle range 
between $0^{\circ}$ (along surface normal) and $75^{\circ}$. They found that apparent emissivity is a maximum for $0^{\circ}$ and decreases consistently to $75^{\circ}$. All such measurements found the emissivity $\epsilon>0.96$. This translates into up to nearly a $2{ }^{\circ} \mathrm{C}$ difference between measured and real temperature at a 75 degree photographic angle, and less than a $0.5^{\circ} \mathrm{C}$ difference for angles between 0 and 30 degrees, with most of the error occurring at wavelengths greater than $11 \mu \mathrm{m}$.

Conversely, from the work in clumping undisturbed powders described above in Sect. 6.2, using an infrared thermometer along the 70 degree photographic angle was recommended by Salisbury et al. (1994b) as an accurate measure of true skin surface temperature. In the case of snow, this means capturing the surface temperature of the grains actually at the very surface.

For fresh snow, these two factors - clumping and photographic angle variation - may combine to complicate the separation between brightness temperature and the actual desired measurement. Figure 3 shows a series of photographs of clumping new dry snow, all of the same area at 0,30 and 75 degree photographic angles. The warm underlayer is significantly more apparent at 0 degrees than at 75 . One may see that the uppermost layer - the peaks of the clumps which are also the coldest portions of the snow - are the primary thermal features captured at a $75^{\circ}$ photographic angle. In contrast, the $0^{\circ}$ photographic angle captures the warmer and lower - valley features between the clumps as well.

So on one hand, photographs at a shallow photographic angle, such as $75^{\circ}$, will experience less emission and perhaps measure a cooler temperature than desired. On the other hand, direct photographs at a photographic angle of 0 degrees may capture the warmer layer below the cooler porous surface snow. In short, the preferred angle of thermography will depend greatly on the application, especially given the possible clumping and the thin active thermal skin discussed above.

To assess the effect of photographic angle at small spatial scales, 15 experiments were performed taking thermographs at various angles to the surface. All photos were taken at a $70 \mathrm{~cm}$ distance from a $20 \times 20 \mathrm{~cm}$ square area of natural snow surface, and each area was photographed at angles of $75,60,45,30$, and 0 degrees (five angles), from four different sides. This gave 20 thermographs per experiment and 300 photographs in total. An averaged area of approximately 10000 pixels per thermograph gave an average temperature measurement for each experiment, side, and photographic angle. The photographs were taken in a different order for each experiment. The imaged areas varied, as did snow surface conditions (moist, dry, new, aged seasonal), time of experiment (from 07:00 to 22:00 h, local time), and average snow surface temperature (between -0 and $-10^{\circ} \mathrm{C}$ ).

To assess trends in the combined data, each experiment mean was re-centered at $0^{\circ} \mathrm{C}$. The resulting deviations from the mean were plotted in $\mathrm{R}$ ( $\mathrm{R}$ Development Core Team, 2006). From this, the brightness temperatures were found to correlate with photographic angle (Pearson's $r=-0.41$, $p<10^{-4}$ ) but had a stronger correlation with the order that the photographs were taken in, as discussed in Sect. 6.4 below.

A least-squares linear regression fitting to the data found the slope of the relationship between photographic angle and apparent temperature to be $-0.0067^{\circ} \mathrm{C}$ of temperature $\left(p<10^{-3}\right)$ per degree of photographic angle. This translates to $0.5^{\circ} \mathrm{C}$ between a direct 0 degree angle photo and a very shallow 75 degree angle photo. This is approximately one-half to one-quarter of the difference found by Dozier and Warren (1982).

The residuals, when viewed on a $\mathrm{Q}-\mathrm{Q}$ plot for normality, follow a reasonable but not precisely $45^{\circ}$ linear relation. This implies that with a more extensive data set including an adequate examination of each specific condition (e.g. snow crystal type, size, and free moisture) a curved relationship might be extracted. Figure $4 \mathrm{a}$ shows the experiment data and the corresponding linear model.

\subsection{Effect of operator heating}

Measurements of snow temperature require that the observer be well insulated from the sample - by distance, clothing, etc. - in order to prevent operator heating.

Since human skin has an emissivity $\epsilon$ of 0.98 , one sees by Eq. (1) that an unclothed human with $27^{\circ} \mathrm{C}$ skin radiates $450 \mathrm{~W} \mathrm{~m}^{-2}$, and a snow surface at $-3{ }^{\circ} \mathrm{C}$ radiates $295 \mathrm{~W} \mathrm{~m}^{-2}$. This yields around 155 radiative $\mathrm{W} \mathrm{m}^{-2}$ power for human skin to heat up a snow surface in the infrared spectrum, minus (a) the effect of any insulation such as clothing and (b) the effect of distance between the observer and the snow decreasing the power density.

The data from the photographic angle experiments described in Sect. 6.3 also revealed a strong correlation with the order in which the thermographs were taken (Pearson's $\left.r=0.70, p<10^{-4}\right)$. Least-squares linear regression on the data revealed a slope of $0.052{ }^{\circ} \mathrm{C}$ increase per photo taken $\left(p<10^{-3}\right)$. As an average experimental run of twenty angled images would take approximately ten minutes, and while taking photographs the operator was $\sim 1 \mathrm{~m}$ away from the sample, this implies an operator effect of $0.1^{\circ} \mathrm{C}$ heating per minute while being within $1 \mathrm{~m}$ of a sample. Figure $4 \mathrm{~b}$ shows the experiment data and the corresponding linear model.

Thus, it takes an operator - wearing a down jacket and ski pants - approximately ten minutes to heat up the surface of a small snow sample $1 \mathrm{~m}$ away by $1^{\circ} \mathrm{C}$.

Additional cold lab experiments were performed to show that a bare hand within millimeters of snow will warm the snow surface nearly instantaneously. These experiments also showed it takes only around a minute for a hand in the same setup to warm $\mathrm{a}-15^{\circ} \mathrm{C}$ snow surface by 6 to $10^{\circ} \mathrm{C}$ in places, depending on the crystal morphology. 


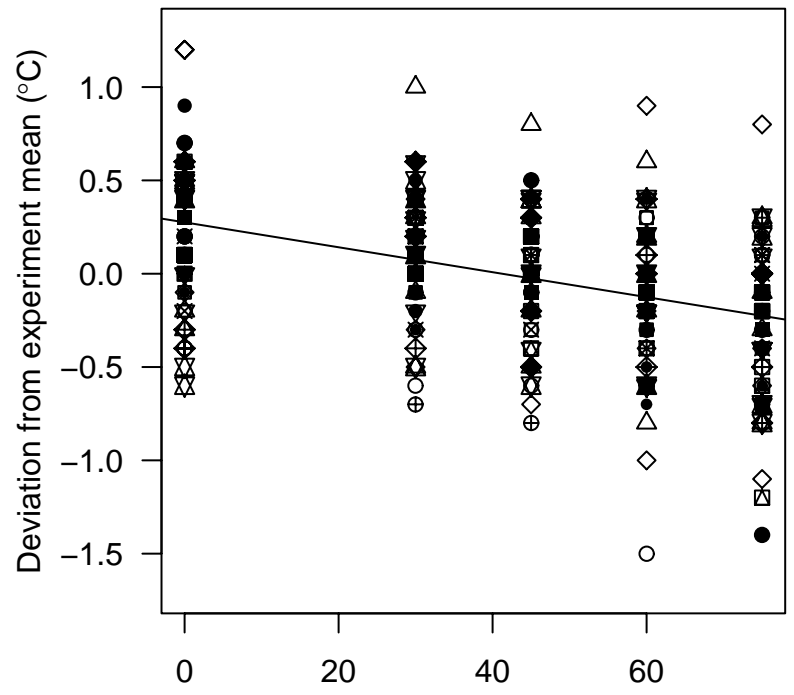

Photographic angle $\left(^{\circ}\right)$

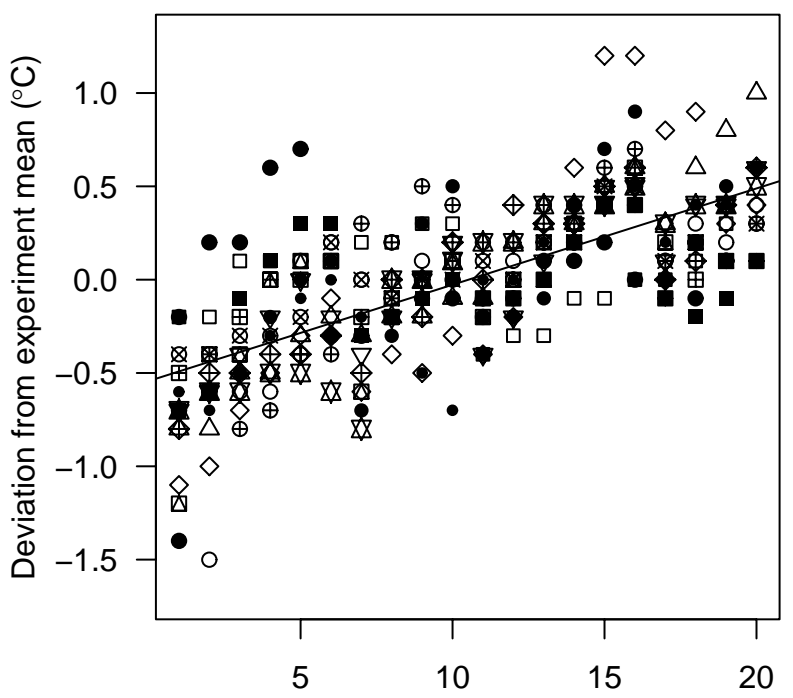

Photograph number (b)

Fig. 4. (a) Relationship between apparent surface temperature and photographic angle, with fit linear model. (b) Relationship between surface temperature and order in which the thermograph was taken, with fit linear model. Both graphs display each experiment with distinct symbols, and the mean of each experiment has been re-centered to $0^{\circ} \mathrm{C}$ to show cross-experiment trends.

Such extremity of operator heating probably only holds true for these very close ranges between operator and sample. This topic warrants further study since (a) specific methods (such as insulation) to mitigate operator heating are asyet untested, and (b) it very probably affects many snow pit temperature measurements. An example of the latter is seen below in Sect. 7.1, where extended operator heating and atmospheric heating penetrates at least to the depth of a short thermometer inserted into the snowpack.

\section{Applications}

Ideal snow surface thermography applications are those which need contactless measurement, benefit from an instantaneous spatial image, and have minimal influence from the considerations discussed above in Sects. 6.1 through 6.4. A selection of applications are presented below.

\subsection{Thermal profiles}

Hand-held thermography can be used to visualize the spatial variation of surface temperatures in a pit wall. Thermal profiles were created by overlapping multiple thermographs, with 6 to 10 thermographs per pit profile. The multiple thermographs per pit provide redundancy and show the relative stability of the thermal measurements over multiple photos. Point measurements from these photos came from the latest photo containing the point of interest, to mimic the thermometer being iteratively placed lower and lower along the pit wall over time.
To confirm the accuracy of these photographs, a standard temperature profile (Canadian Avalanche Association, 2007) was also taken with a calibrated point thermistortype thermometer inserted $\sim 12 \mathrm{~cm}$ into the pit wall, in the classic method of temperature profiling (Fierz, 2010). Although thermograph measurements deviated from the handheld thermometer by up to $2^{\circ} \mathrm{C}$, the relationship between traditional point and thermograph measurements have a Pearson's correlation of $r=0.96, p<10^{-4}$.

Figure 5 shows a three-stage progression of a profile obtained in this manner. It shows a thermograph from a freshly dug pit (1), a thermograph from the same pit $\sim 2$ min later (2), and a standard point temperature profile taken in the same pit immediately after that (3). The thermographs are layered to put the values used in (3) on top, that is, the first photos are under the later photos of the same area. In this way, the effect of operator heating and atmospheric changes on the surface may be seen over time, as well as the penetration of these effects into the snowpack. Note that the uneven pit wall areas, such as irregularities from shovel blade use, display photographic angle effects.

After the experiments were concluded (after approximately 30 elapsed minutes), $\sim 30 \mathrm{~cm}$ of surface snow was removed from a portion of the exposed pit wall, and a downward-looking thermograph confirmed horizontal heat penetration at depths 10 to $18 \mathrm{~cm}$ from the pit wall, with isolated patches of deeper penetration. However, one should note that the traditional point measurements of (3) occurred behind the snow surface at the length of the thermometer shaft, and thus slope-parallel spatial variation behind the pit wall may also play a role in those values. 


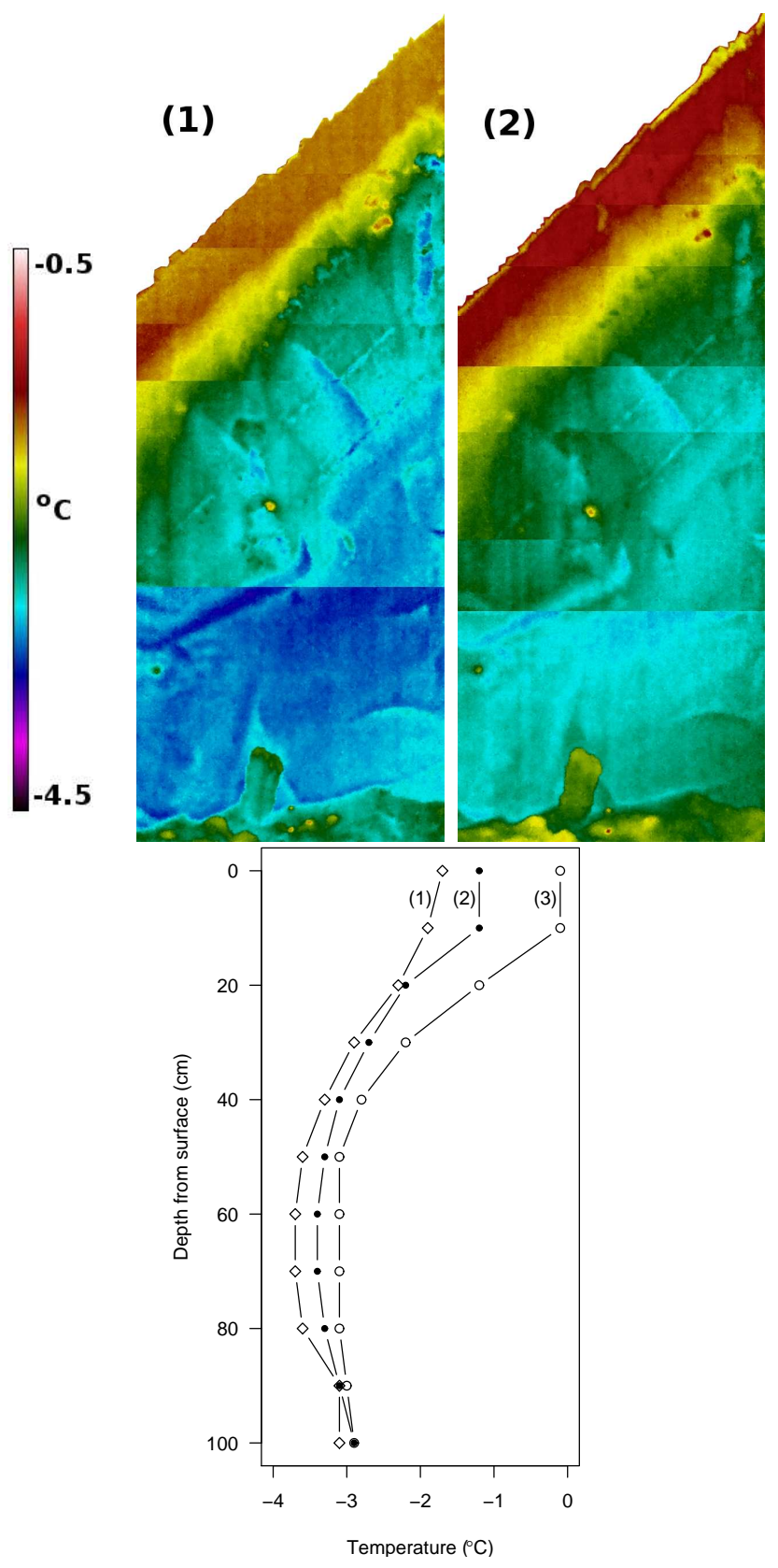

Fig. 5. Two thermography temperature profiles of the same pit, in order of time photographed ( 1 then 2 ), and one temperature profile performed in the same pit (3, in graph). For scale, the warmer layer near the surface (appearing as red) is $\sim 10 \mathrm{~cm}$ vertical width. The effect of operator heating and atmospheric heating is visualized between (1) and (2), and the effect of atmospheric and operator heating at depth combined with spatial variation is visualized by adding point profiles from 1 and 2 to the graph containing profile 3 .

\subsection{Differing thermal conductivity}

Snow conduction has been linked with snow density under the general theory that the denser the snow, the more bonds per volume, and thus the more paths for conduction (Armstrong and Brun, 2008, p. 36). However, recent research has shown that thermal conduction through snow is a spatially complex phenomenon, with conductive chains evolving generally but tortuously along a thermal gradient (Schneebeli and Sokratov, 2004). Other than that work, modelling, and bulk measurement, visualization and measurement of thermal conduction through snow is currently limited.

In a temperature-controlled lab at $-15^{\circ} \mathrm{C}, 2 \mathrm{~cm}$ thick snow samples were heated from behind using a $175 \mathrm{~W}$ infrared bulb. Samples of previously moist and subsequently refrozen rounded grains and polycrystals (RGlr and MFpc, respectively, as classified by Fierz et al., 2009) were compared using time-lapse thermal video. The samples were extracted as they lay slope parallel by removing the snow above and below. These layers were then turned on end, heated for three minutes from behind, and allowed to cool for nine minutes each. The polycrystals measured to $6 \mathrm{~mm}$ in extent and had a density of $270 \mathrm{~kg} \mathrm{~m}^{-3}$; the rounded grains measured to $0.5 \mathrm{~mm}$ in extent and had a density of $390 \mathrm{~kg} \mathrm{~m}^{-3}$.

Figures 6 and 7 show frames from these time lapse videos. It is apparent from these videos that although the polycrystal layer had a much lower density, it was a faster conductor. Further, this particular layer of polycrystals appears much more spatially variable as a conductor, although perhaps this may be due to not being able to view the individual crystals in the sample of rounds.

Although emissivity may not vary much by crystal morphology, these videos show that conductivity does vary substantially. This form of visualization is quite new - only recently have advances in snow and radiation modelling (Kaempfer et al., 2007) enabled infrared reflection, refraction, and absorption to be modelled and visualized, and such methods operate on a per-photon level using lattice models of real snow.

\subsection{Additional applications}

Thermal effects occur many places without our explicit knowledge. This section outlines additional applications at a high level, in order to show the breadth of application available. Beyond specific interest for avalanches, handheld thermography has wide application for the snow sciences generally, from providing confirmation data for spatial surface radiative balance models on glaciers, to detecting the effects of wind pumping. 


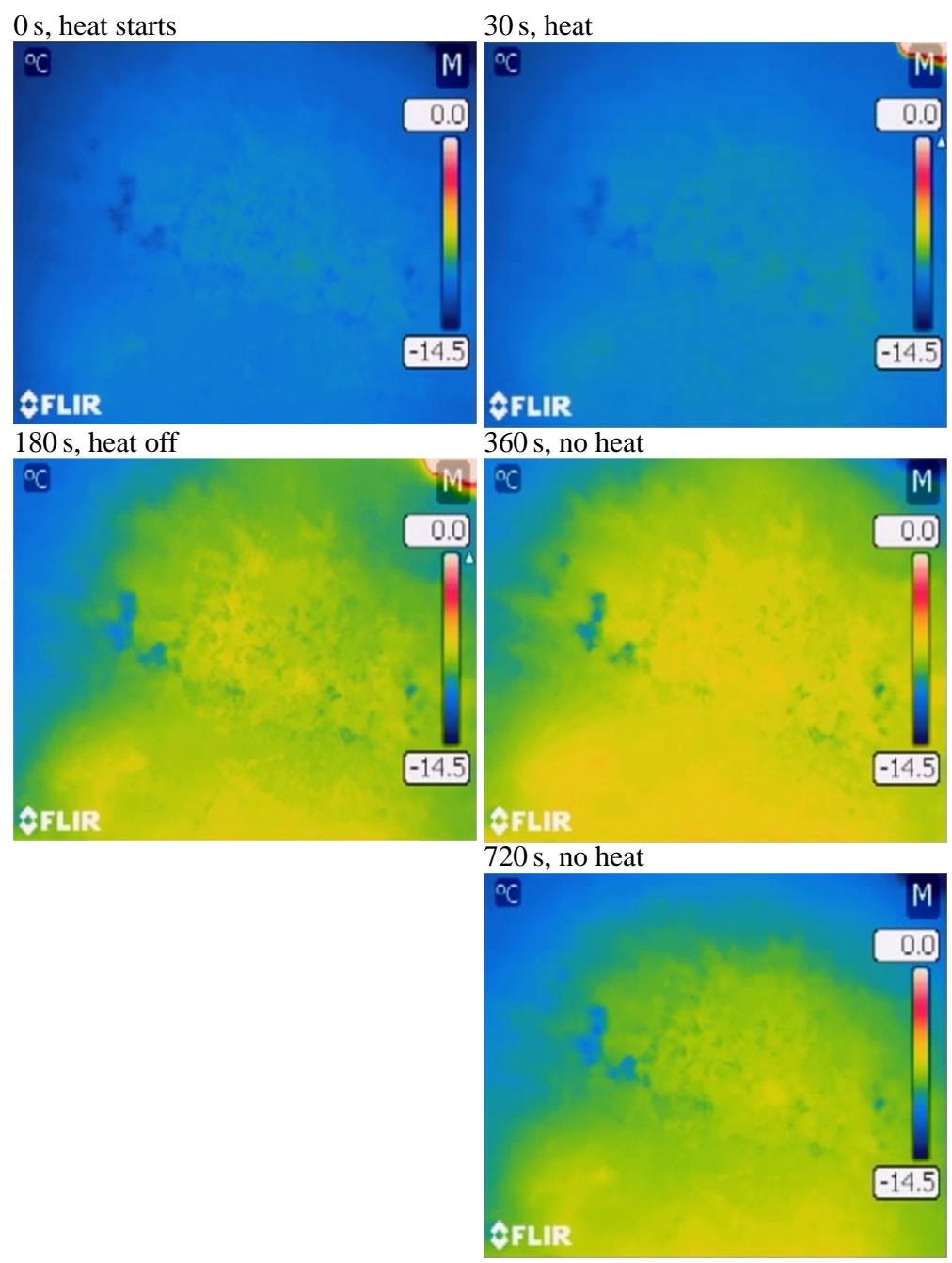

$90 \mathrm{~s}$, heat

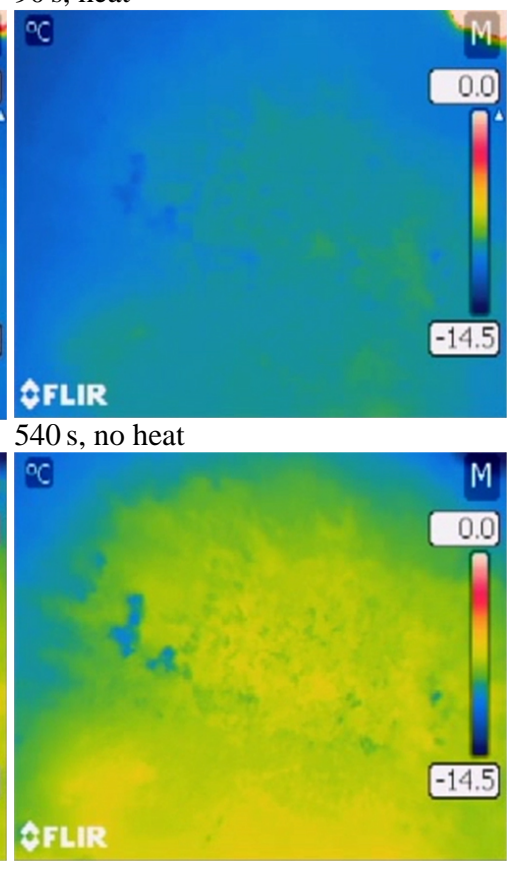

Fig. 6. Seven frames of video from a $2 \mathrm{~cm}$ thick slice of a layer of rounded grains. The layer has crystals with extent to $0.5 \mathrm{~mm}$ and density of $390 \mathrm{~kg} \mathrm{~m} \mathrm{~m}^{-3}$. Heat was applied behind the sample from 0 to $180 \mathrm{~s}$. Sample width in each image is $\sim 10 \mathrm{~cm}$.

\section{Melt tracking}

The meltwater penetrating the snow in Fig. 8a shows that the heat transfer from liquid water into the snow can be captured using thermography. This particular thermograph shows that the fingers of melt maintain a tight radius of heat around the wet area with minimal conduction beyond that.

\section{Effect of vegetation}

Although thermography measures surface temperatures only, it can be useful in measuring thermal qualities caused by buried objects. In Fig. 8b, a buried bush conducts heat upwards and creates a warmer area on the surface. Bushes often affect the internal snow temperature gradient around them and are associated with facet growth. Thermography would have application to these studies, both in measuring heat at the surface and, with excavation, studying the associated temperature gradients around the objects themselves.
Although shallowly buried bushes are easily seen on thermographs, the application of thermography to avalanche rescue seems limited. The bushes have been buried long enough for their heat to conduct to the surface to be seen, and it is this conduction time that would make thermography ineffective in detecting buried humans in a timely manner. Previous work at the Icelandic Meterological Office used barrels of warm water buried under the snow at various depths $(0.5$, 1.0 and $1.5 \mathrm{~m}$ ) and thermal cameras to examine any possible clues of that heat being detected at the surface. More than two hours elapsed before the experimenters stopped timing and probed into the snow down to the barrels, confirming that the heat was detectable through the air in the probe holes but not on the snow surface (Jonsson and Svavarsson, 1995). 

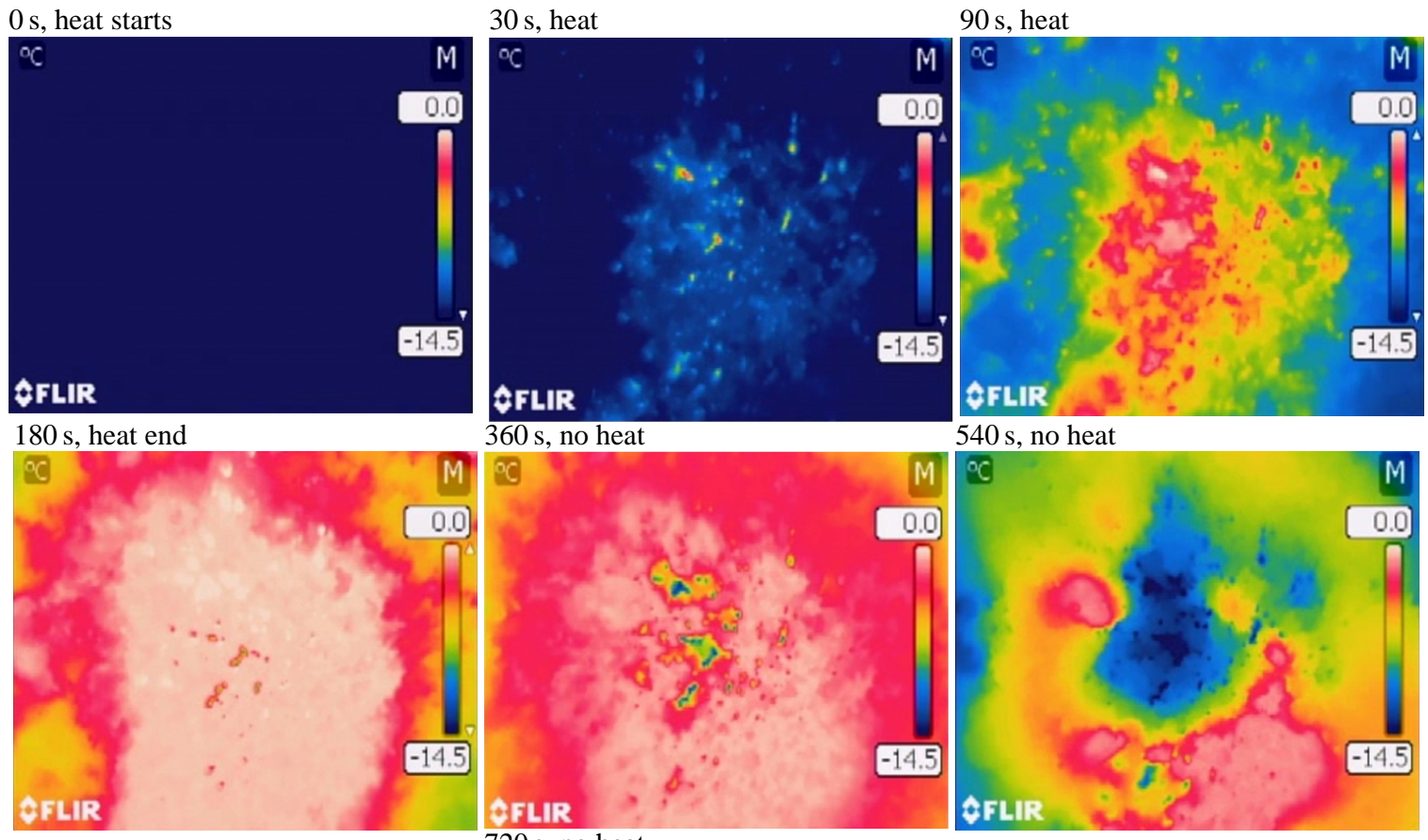

\section{$360 \mathrm{~s}$, no heat}

$540 \mathrm{~s}$, no heat

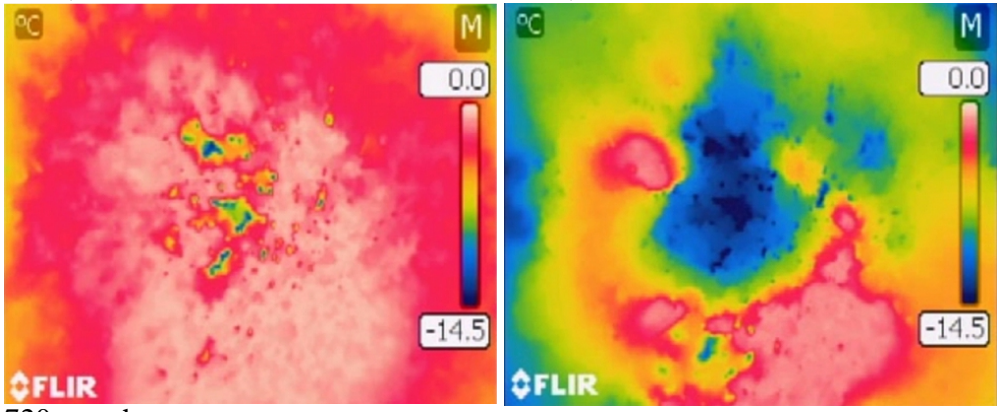

$720 \mathrm{~s}$, no heat

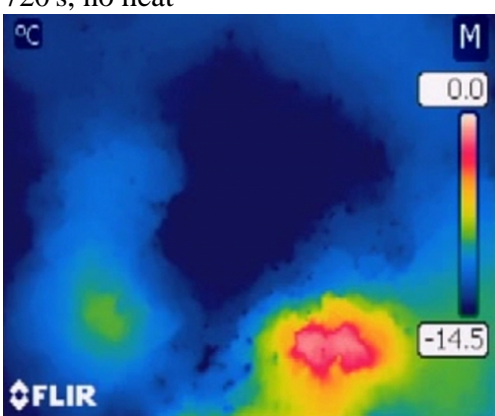

Fig. 7. Seven frames of video from a $2 \mathrm{~cm}$ thick slice of a layer of polycrystals. The layer has crystals with extent to $6 \mathrm{~mm}$ and density of $270 \mathrm{~kg} \mathrm{~m}^{-3}$. Heat was applied behind the sample from 0 to $180 \mathrm{~s}$. Sample width in each image is $\sim 10 \mathrm{~cm}$.
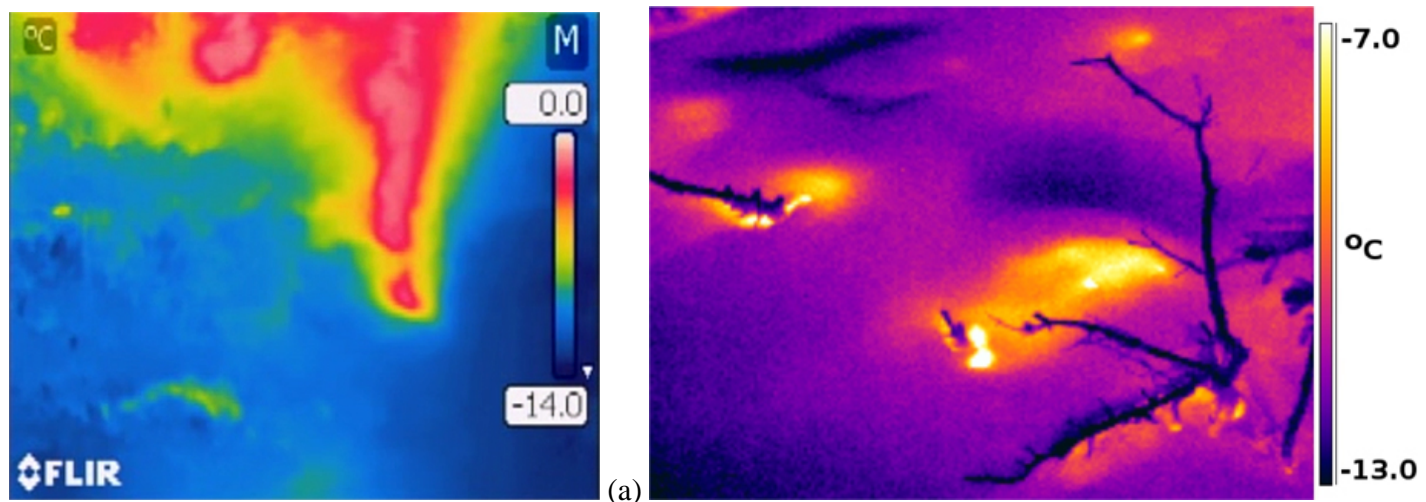

(b)

Fig. 8. Two different types of heat penetration into snow. (a) A video frame of fingers of melt penetrating the surface of the snow after 20 min of heating. The fingers are up to $6 \mathrm{~cm}$ long. (b) Hibernating bushes are cold above the snow, but still transport heat from the ground to warm the snow from below. The image spans $\sim 1 \mathrm{~m}$. 

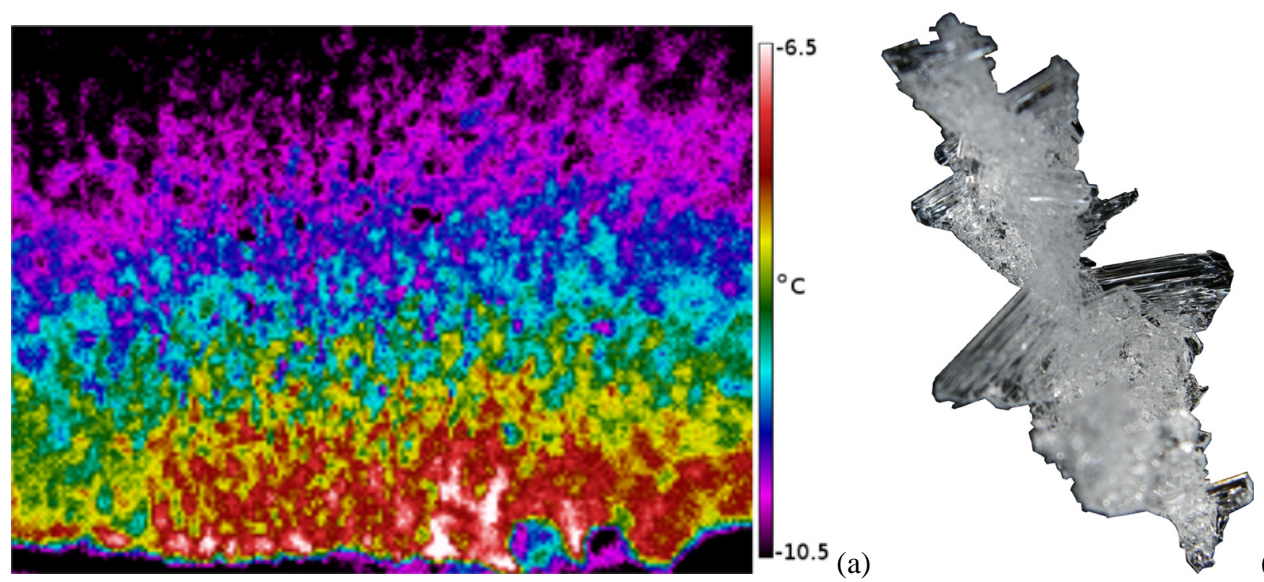

(b)

Fig. 9. Thermal application in crystal metamorphosis. (a) An apparent phenomenon of thermal chaining, where chains of mature faceted crystals form aligned from the ground (bottom of image) to the snow surface (top of image). These crystals display physical connection and subsequent isothermal tendencies. They appear as isothermal fingers pointing from the base upwards. The image spans $\sim 30 \mathrm{~cm}$ in width. (b) A physical depth hoar chain extracted from a similar layer, length $\sim 40 \mathrm{~mm}$.

\section{Satellite downscaling}

As discussed in the introduction, some satellites providing space-based remote sensing measurements yield data in the thermal range, including Landsat and MODIS. These platforms average large areas - from $60 \mathrm{~m}$ to more than $1 \mathrm{~km}-$ in one pixel worth of data. Handheld thermography could aid in studying the conditions of interest for downscaling this space-based data. Also, as discussed in Sect. 6.3, previous studies have used hemispherical thermal-range sensors to address corrections needed for different angles of spacebased data acquisition. Handheld thermography can also study photographic angle effects, as shown earlier.

\section{Crystal metamorphosis}

Previous work in $\mu \mathrm{CT}$ tomography (Schneebeli and Sokratov, 2004) demonstrates that ice crystal metamorphosis under a strong temperature gradient will develop growth preferentially along the temperature gradient. Designing an equipment setup to allow a thermal camera - with a macro lens to view and record the thermal metamorphosis on one surface of a $\mu \mathrm{CT}$ sample would be complex. However, examining the microstructure of crystals exposed to steep and prolonged temperature gradients in a natural environment may provide supporting data for that sought through tomography. Figure 9 shows that crystals can form chains along these natural temperature gradients from ground to surface, and that such chains display isothermal tendencies that we call thermal chaining.

\section{Summary and conclusions}

This paper has discussed the physical basis for thermography, summarized previous work in snow thermal emissivity, addressed handheld thermography concerns specific to snow, and presented a few of the possible applications. On one hand, snow is easy to thermally image due to its high emissivity; on the other hand, complications such as the solid state greenhouse effect, the need to correct for observer heating, the application-specific choice of photographic angle, and the influence of water vapour in the atmosphere all contribute to making thermography a careful endeavor.

Despite this, thermography is a powerfully spatial and visual measurement method. It can help measure and visualize everything from heat conduction to instantaneous spatial temperatures. It is our hope that this paper inspires further work using this technique.

\section{Supplementary material related to this article is available online at: http://www.the-cryosphere.net/5/55/2011/ tc-5-55-2011-supplement.zip.}

Acknowledgements. For logistical support, we are very grateful to the Avalanche Control Section of Glacier National Park. For careful field work, we thank Mike Smith, Katherine Johnston, David Tracz, and Sascha Bellaire.

For financial support, we thank the Natural Sciences and Engineering Research Council of Canada, HeliCat Canada, the Canadian Avalanche Association, Mike Wiegele Helicopter Skiing, Teck Mining Company, Canada West Ski Areas Association, the Association of Canadian Mountain Guides, Backcountry Lodges of British Columbia, and the Canadian Ski Guides Association. 
Also thank you to Thomas Kaempfer, then of the USA Cold Regions Research Engineering Laboratory, for the initial idea that thermography might be used to measure snow surface processes, and Arni Jonsson who provided a reference for previous attempts to use thermography in avalanche rescue.

Edited by: A. Klein

\section{References}

Armstrong, R. L. and Brun, E.: Snow and Climate: Physical Processes, Surface Energy Exchange and Modeling, Cambridge University Press, Cambridge, United Kingdom, 2008.

Brandt, R. E. and Warren, S. G.: Solar-heating rates and temperature profiles in Antarctic snow and ice, J. Glaciol., 39, 99-110, 1993.

Canadian Avalanche Association: Observational Guidelines and Recording Standards for Weather, Snowpack and Avalanches, Canadian Avalanche Association, Revelstoke, British Columbia, Canada, 2007.

Dozier, J. and Warren, S. G.: Effect of Viewing Angle on the Infrared Brightness Temperature of Snow, Water Resour. Res., 18, 1424-1434, 1982.

Fierz, C.: Encyclopedia of Snow, Ice and Glaciers, edited by: Singh, V., Singh, P., and Haritashya, U. K., Springer Publishing, New York, 2010.

Fierz, C., Armstrong, R., Durand, Y., Etchevers, P., Greene, E., McClung, D., Nishimura, K., Satyawali, P., and Sokratov, S.: The International Classification for Seasonal Snow on the Ground, IHP-VII Technical Documents in Hydrology N. 83, IACS Contribution N. 1, UNESCO-IHP, Paris, 2009.

Hachikubo, A. and Akitaya, E.: Effect of wind on surface hoar growth on snow, J. Geophys. Res., 102, 4367-4373, 1997.

Hori, M., Aoki, T., Tanikawa, T., Motoyoshi, H., Hachikubo, A., Sugiura, K., Yasunari, T., Eide, H., Storvold, R., Nakajima, Y., and Takahashi, F.: In-situ measured spectral directional emissivity of snow and ice in the $8-14 \mu \mathrm{m}$ atmospheric window, Remote Sens. Environ., 100, 486-502, 2006.
Jonsson, A. and Svavarsson, L. O.: Search for avalanche victims with a heat camera, Experiment at Blue mountain area, Unpublished letter to the Director of the Civil Defense in Iceland, 5 June 1995.

Kaempfer, T., Hopkins, M., and Perovich, D.: A threedimensional microstructure-based photon-tracking model of radiative transfer in snow, J. Geophys. Res., 112, D24113, doi:10.1029/2006JD008239, 2007.

Lillesand, T., Kiefer, R., and Chipman, J.: Remote Sensing and Image Interpretation, Sixth Edition, John Wiley and Sons, 2008.

McClung, D. and Schaerer, P.: The Avalanche Handbook, Third Edition, The Mountaineers Books, Seattle, WA, 2006.

Morstad, B., Adams, E., and McKittrick, L.: Experimental and analytical study of radiation-recrystallized near-surface facets in snow, Cold Reg. Sci. Technol., 47, 90-101, 2007.

R Development Core Team: R: A Language and Environment for Statistical Computing, R Foundation for Statistical Computing, Vienna, Austria, http://www.R-project.org, last access: $23 \mathrm{Au}$ gust 2010, ISBN 3-900051-07-0, 2006.

Salisbury, J. W., D'Aria, D. M., and Wald, A.: Measurements of thermal infrared spectral reflectance of frost, snow, and ice, J. Geophys. Res., 99, 24235-24240, 1994a.

Salisbury, J. W., Wald, A., and D'Aria, D. M.: Thermal infrared remote sensing and Kirchoff's law: 1. Laboratory measurements, J. Geophys. Res., 99, 11897-11911, 1994b.

Schneebeli, M. and Sokratov, S.: Tomography of temperature gradient metamorphism of snow and associated changes in heat conductivity, Hydrol. Process., 18, 3655-3665, 2004.

Sugita, M. and Brursaert, W.: Cloud effect in the estimation of instantaneous downward longwave radiation, Water Resour. Res., 29, 599-605, 1993.

Wolfe, W. L. and Zissis, G. J.: The Infrared Handbook, The Infrared Information and Analysis Center (IRIA) Center, Environmental Research Institute of Michigan, prepared for The Office of Naval Research, Department of the Navy, Washington, DC and Arlington, VA, 1978. 